\title{
Efeito da freqüência e altura de poda na produtividade de raízes e parte aérea em mandioca ${ }^{(1)}$
}

\author{
Geraldo de Melo Moura(2) e Newton de Lucena Costa(3)
}

\begin{abstract}
Resumo - O objetivo do presente trabalho foi avaliar o efeito da altura e freqüência de poda, sobre a produtividade de parte aérea e de raízes em cinco cultivares de mandioca. Foram avaliadas duas alturas $(0,50 \mathrm{~m}$ e $1,00 \mathrm{~m})$ e três freqüências de poda (aos 6, 12 e 18 meses, aos 12 e 18 meses e aos 18 meses), envolvendo as cultivares Paxiubão, Pretinha, Paxiúba II, Metro III, e Pirarucu. A produção de matéria verde e a porcentagem de folhas foram inversamente proporcionais à idade das plantas. Com exceção da cultivar Paxiubão, os rendimentos de raízes foram reduzidos com o aumento da freqüência de podas. O rendimento de raízes foi reduzido tanto pela altura como pela freqüência de poda, enquanto o rendimento de matéria verde foi influenciado pela freqüência de poda. A altura e a freqüência de poda reduziram o teor de matéria seca de raízes e elevaram o índice de podridão de raízes. A freqüência de poda reduziu o teor de ácido cianídrico nas raízes. Para o aproveitamento simultâneo da parte aérea e raízes recomenda-se a cultivar Paxiubão com poda aos 6 e 12 meses.
\end{abstract}

Termos para indexação: Manihot esculenta, matéria seca, podridão da raiz, ácido cianídrico.

\section{Effect of frequency and height of pruning on root and shoot productivity in cassava}

\begin{abstract}
The objective of the present work was to evaluate the effect of height and frequency of pruning on productivity of aerial part and roots of five cultivars of cassava. Two heights $(0.50 \mathrm{~m}$ and $1.00 \mathrm{~m}$ ) and three frequencies of prunings (at 6,12 and 18 months, at 12 and 18 months and at 18 months) were evaluated using the cultivars Paxiubão, Paxiúba II, Metro III, Pretinha and Pirarucu. The production of green mass and limb percentage were inversely proportional to plant age. Except in the cultivar Paxiubão, root yield was reduced with the increase of pruning frequency. Root yield was reduced by the pruning height as much as by the pruning frequency, while the yield of green mass was influenced by the pruning frequency. Pruning height and pruning frequency reduced the content of root dry matter and elevated the index of root rot. Pruning frequency reduced the content of hydrocyanic acid in the root. The cultivar Paxiubão is recommended for simultaneous use of aerial part and root, with pruning at 6 and 12 months.
\end{abstract}

Index terms: Manihot esculenta, dry matter, root rots, hydrocyanic acid.

\section{Introdução}

Durante a colheita da mandioca (Manihot esculenta Crantz), apenas parte da haste lenhosa é usada para novos plantios, e o restante é deixado no campo e incorporado ao solo como fonte de matéria

\footnotetext{
(1) Aceito para publicação em 25 de setembro de 2000 .

(2)Embrapa-Centro de Pesquisa Agroflorestal do Acre (CPAF-Acre), Caixa Postal 392, CEP 69901-180 Rio Branco, AC. E-mail: geraldo@cpafac.embrapa.br

(3)Embrapa-Centro de Pesquisa Agroflorestal do Amapá (CPAF-Amapá), Caixa Postal 10, CEP 68902-280 Macapá, AP. E-mail: newton@cpafap.embrapa.br
}

orgânica. A falta de conhecimento, pelos produtores, da importância de seu uso na alimentação animal, tem contribuído para o baixo aproveitamento desta fonte de proteína, principalmente durante o período seco, quando a produtividade e qualidade das pastagens são acentuadamente reduzidas. A possibilidade do armazenamento da parte aérea sob a forma de feno ou silagem tornaria viável sua utilização durante os períodos críticos de alimentação dos rebanhos, além de diminuir consideravelmente os custos de produção na propriedade (Carvalho et al., 1983).

As cultivares de mandioca diferem quanto à produtividade, da parte aérea e das raízes, o que permite sua seleção de acordo com a finalidade a que se des- 
tinam. No Pará, Batista et al. (1983a, 1983b), avaliando 30 cultivares de mandioca, concluíram que as mais adaptadas à produção de forragem apresentaram rendimentos de 13,7,10,8 e 10,0 t/ha de matéria verde. Carvalho et al. (1985), na Bahia, verificaram que as cultivares de maior destaque, entre as dez avaliadas, apresentaram produções de 13,8,11,8 e 10,8 t/ha de matéria verde. Em Porto Velho, Rondônia, as cultivares selecionadas para produção de forragem apresentaram rendimentos de 5,9 t/ha, 5,6 t/ha e 5,0 t/ha (Oliveira \& Lima, 1986).

Na seleção de cultivares para a produção de forragem, um fator a ser considerado é a partição diferencial da parte aérea da planta (porcentagem de caule, limbo e pecíolo), já que apenas a parte enfolhada da planta é aproveitável, o que corresponde aproximadamente ao seu terço superior. Neste sentido, Montaldo (1977), avaliando a distribuição das diferentes porções da parte aérea de 11 clones de mandioca, verificou maior proporção de lâminas foliares e hastes mais pecíolos, nas plantas cortadas aos quatro meses, em comparação com as cortadas aos oito meses. No Pará, Camarão et al. (1993) encontraram maiores porcentagens de limbo nas cultivares Acreana $(53,3 \%)$, Tataruaia $(51,9 \%)$ e IAN II $(50,9 \%)$.

A freqüência e intensidade de poda são fatores responsáveis pela queda da produção de raiz. Em geral, podas tardias e pouco intensas não afetam a produção de raízes; no entanto, podas freqüentes e intensas favorecem a produção de forragem (Ahmad, 1973; Correa et al., 1973; Montaldo \& Montilla, 1977; Gerodetti, 1979). Teeluck et al. (1981), obtiveram produções de 44,5 t/ha de matéria verde, com uma composição de $36 \%$ de folhas e pecíolos e $64 \%$ de hastes, utilizando cortes entre 10 e $15 \mathrm{~cm}$ acima do solo, e a intervalos de três a cinco meses. Já Meyreles et al. (1977), realizando podas a $40 \mathrm{~cm}$ acima do solo, em duas cultivares com cinco meses de idade, estimaram produções de matéria verde de 65,7 e $40,6 \mathrm{t} / \mathrm{ha}$.

Segundo Albuquerque \& Cardoso (1980), o aumento da idade das plantas exerce marcante influência na produção de folhas, as quais vão caindo com o avanço da idade das plantas, processo que se intensifica do $6^{\circ}$ ao $18^{\circ}$ mês após o plantio. Resultados semelhantes foram obtidos na Bahia por Fukuda \& Caldas (1985), que avaliaram clones e cultivares de mandioca. Os autores verificaram que o corte aos 24 meses proporcionou um incremento de apenas $5 \%$ na produção da parte aérea, em comparação com o corte aos 18 meses.

Muitos estudos já foram realizados sobre o efeito da poda na produção de raízes e parte aérea; porém, a experimentação local torna-se necessária, tendo em vista as peculiaridades ecológicas, as cultivares empregadas e suas interações.

Este trabalho teve por objetivo avaliar a produtividade da parte aérea e de raízes de cinco cultivares de mandioca locais, submetidas a diferentes freqüências e alturas de poda.

\section{Material e Métodos}

O trabalho foi conduzido no campo experimental da Embrapa-Centro de Pesquisa Agroflorestal do Acre, localizado no Município de Rio Branco, Acre ( $9^{\circ} 58^{\prime} 29^{\prime \prime}$ de latitude Sul e 67० 48' 36" de longitude Oeste), durante o período de novembro de 1996 a maio de 1998. Os solos predominantes no município pertencem à classe Podzólico Vermelho-Amarelo eutrófico. O clima é tropical, do tipo Am, de acordo com a classificação de Köppen, quente e úmido, com estações seca (junho a setembro) e úmida (outubro a maio, com chuvas constantes) bem definidas (Oliveira \& Alvarenga, 1985).

O delineamento experimental utilizado foi o de blocos casualizados, com quatro repetições. Os tratamentos foram arranjados num fatorial $5 \times 3 \times 2$, e consistiram de cinco cultivares de mandioca, três freqüências de podas e duas alturas de poda. As parcelas ocuparam área útil de $4,5 \mathrm{~m}^{2}$ e foram compostas por nove plantas, no espaçamento de $1,00 \mathrm{~m}$ entre linhas e $0,50 \mathrm{~m}$ entre plantas. O plantio foi realizado em 18/11/96, em uma área ocupada anteriormente por capim-colonião (Panicum maximum Jacq.). O preparo da área constou de uma gradagem pesada e duas gradagens niveladoras; não foi realizada adubação, nem correção do solo. A análise do solo revelou os seguintes resultados: $\mathrm{pH}, 4,7 ; \mathrm{P}, 9 \mathrm{mg} / \mathrm{kg}$; $\mathrm{K}, 66 \mathrm{mg} / \mathrm{kg} ; \mathrm{Ca}, 5,1 \mathrm{cmol}_{\mathrm{c}} / \mathrm{dm}^{3} ; \mathrm{Mg}, 1,1 \mathrm{cmol}_{\mathrm{c}} / \mathrm{dm}^{3}$; Al, $0,2 \mathrm{cmol}_{\mathrm{c}} / \mathrm{dm}^{3}$ e $\mathrm{H}+\mathrm{Al}, 3,8 \mathrm{cmol}_{\mathrm{c}} / \mathrm{dm}^{3}$.

As cultivares utilizadas foram Paxiubão, Paxiúba II, Metro III, Pretinha e Pirarucu. Foram avaliadas três freqüências de poda: na primeira, as mesmas plantas foram podadas aos 6, 12 e 18 meses após o plantio; na segunda, as mesmas plantas foram podadas aos 12 e 18 meses; e na terceira, uma única vez, aos 18 meses. Todas as podas foram efetuadas a duas alturas do solo: 0,50 e 1,00 m acima do solo. Em cada poda determinou-se o rendimento de matéria verde e matéria seca do caule, limbo e pecíolo. 
Os tratos culturais limitaram-se a três capinas manuais, e as raízes foram colhidas imediatamente após a última poda, em 20/5/98.

Por ocasião da colheita, foram destinados cerca de $5,0 \mathrm{~kg}$ de raízes de cada cultivar para a estimativa da matéria seca e do ácido cianídrico. Utilizou-se o método da balança hidrostática sugerido por Grossman \& Freitas (1950), para a estimativa da matéria seca, sendo o teor de ácido cianídrico determinado pelo método de Williams \& Edwards (1980). Foi avaliada também a porcentagem de raízes podres em relação ao número total de raízes colhidas.

\section{Resultados e Discussão}

De acordo com as análises estatísticas, foram significativas as interações: na parte aérea - freqüência de poda $\mathrm{x}$ cultivar e freqüência de poda $\mathrm{x}$ altura de poda x cultivar; nas raízes - cultivar $\mathrm{x}$ freqüência de poda; na matéria seca de raízes e podridão de raízes altura de poda $\mathrm{x}$ freqüência de poda, altura de poda $\mathrm{x}$ cultivar e altura de poda $\mathrm{x}$ freqüência de poda x cultivar; no teor de ácido cianídrico - freqüência de poda $\mathrm{x}$ cultivar. Os desdobramentos destas interações estão apresentados nas Tabelas 1 a 3 .

O rendimento de matéria verde aos 18 meses, resultante da poda a $0,50 \mathrm{~m}$ de altura, oscilou de 66,94 a 34,16 t/ha (96\%), enquanto a 1,00 m a variação foi de 52,50 a $33,28 \mathrm{t} / \mathrm{ha}(57,7 \%)$, mostrando assim, que algumas cultivares produzem mais massa de caule até 1,00 $\mathrm{m}$ de altura do que outras (Tabela 1). Essa variação é decorrente das diferentes características inerentes a cada cultivar, relativas à altura da planta e ao índice de área foliar. Estes resultados são semelhantes aos obtidos por Kato et al. (1985), que avaliaram diversas cultivares de mandioca na região de Altamira, PA, cujos rendimentos de matéria verde variaram de 61,7 a 43,0 t/ha. No entanto, são superiores aos obtidos por Carvalho et al. (1985) e Batista et al. (1983a, 1983b), que obtiveram rendimentos de 13,8 a 10,0 t/ha.

Com relação à freqüência de poda, a matéria verde resultante de duas ou três podas a $0,50 \mathrm{~m}$ de altura não se diferenciou $(\mathrm{P}>0,05)$ da obtida com a realização de apenas uma poda, com exceção da cultivar Paxiubão, onde uma poda foi inferior às demais. Resultados diferentes foram relatados por Pezo et al. (1984), que constataram que a matéria seca resultante dos regimes de poda a cada dois, três ou quatro meses, foi superior à obtida no regime de apenas um corte por ocasião da colheita. Com podas a $1,00 \mathrm{~m}$ acima do solo, a freqüência de duas podas foi superior às demais, nas cultivares Metro III, Pretinha e Paxiubão (Tabela 1). Já a poda única a $1,00 \mathrm{~m}$ de altura não se diferenciou das demais freqüências de poda nas cultivares Paxiúba II e Pirarucu.

As forragens oriundas de uma poda aos seis meses (da freqüência de três podas) e uma poda aos doze meses (da freqüência de duas podas) apresentaram

Tabela 1. Rendimento de matéria verde da parte aérea ( $\mathrm{t} / \mathrm{ha}$ ) de cultivares de mandioca submetidas a três freqüências de poda a 0,50 m e a 1,00 m acima do solo. Rio Branco, Acre, 1999(1).

\begin{tabular}{lccc}
\hline Cultivar & \multicolumn{3}{c}{ Podas após plantio } \\
\cline { 2 - 4 } & 6,12 e 18 meses & 12 e 18 meses & 18 meses \\
\hline & & Altura de poda $(0,50 \mathrm{~m})$ \\
Metro III & $51,61 \mathrm{aA}$ & $65,72 \mathrm{aAB}$ & $66,94 \mathrm{aA}$ \\
Paxiúba II & $48,82 \mathrm{aA}$ & $42,77 \mathrm{aB}$ & $57,77 \mathrm{aAB}$ \\
Pretinha & $72,44 \mathrm{aA}$ & $59,50 \mathrm{aAB}$ & $52,22 \mathrm{aAB}$ \\
Pirarucu & $50,61 \mathrm{aA}$ & $71,55 \mathrm{aA}$ & $48,67 \mathrm{aAB}$ \\
Paxiubão & $58,80 \mathrm{aA}$ & $68,33 \mathrm{aAB}$ & $34,16 \mathrm{bB}$ \\
\hline & & \\
Metro III & $43,88 \mathrm{bB}$ & $68,22 \mathrm{aA}$ & $43,89 \mathrm{bA}$ \\
Paxiúba II & $49,89 \mathrm{aB}$ & $54,17 \mathrm{aA}$ & $52,50 \mathrm{aA}$ \\
Pretinha & $43,77 \mathrm{bB}$ & $72,69 \mathrm{aA}$ & $35,55 \mathrm{bA}$ \\
Pirarucu & $54,89 \mathrm{aAB}$ & $54,94 \mathrm{aA}$ & $46,94 \mathrm{aA}$ \\
Paxiubão & $79,77 \mathrm{aA}$ & $60,27 \mathrm{aA}$ & $33,28 \mathrm{bA}$ \\
\hline
\end{tabular}

${ }^{(1)}$ Médias seguidas de mesma letra, minúscula nas linhas e maiúscula nas colunas, não diferem entre si $(\mathrm{P}>0,05)$, pelo teste de Tukey. 
Tabela 2. Rendimento de raiz (t/ha) e teor de ácido cianídrico na polpa $(\mathrm{mg} / \mathrm{kg})$ de cultivares de mandioca submetidas a três freqüências de poda. Rio Branco, Acre, 1999(1).

\begin{tabular}{lccc}
\hline Cultivar & \multicolumn{3}{c}{ Podas após plantio } \\
\cline { 2 - 4 } & 6,12 e 18 meses & 12 e 18 meses & 18 meses \\
\hline & & Rendimento de raiz & \\
Metro III & $24,44 \mathrm{bA}$ & $28,47 \mathrm{bA}$ & $50,14 \mathrm{aAB}$ \\
Paxiúba II & $27,49 \mathrm{bA}$ & $27,78 \mathrm{bA}$ & $62,50 \mathrm{aA}$ \\
Pretinha & $25,55 \mathrm{bA}$ & $37,50 \mathrm{bA}$ & $59,16 \mathrm{bA}$ \\
Pirarucu & $25,27 \mathrm{bA}$ & $29,17 \mathrm{bA}$ & $52,50 \mathrm{aAB}$ \\
Paxiubão & $35,83 \mathrm{aA}$ & $31,25 \mathrm{aA}$ & $38,89 \mathrm{aB}$ \\
\hline Médias & 27,72 & 30,83 & 52,84 \\
\hline & & Ácido cianídrico \\
Metro III & $28,4 \mathrm{bB}$ & $64,1 \mathrm{aA}$ & $61,2 \mathrm{aA}$ \\
Paxiúba II & $61,2 \mathrm{abA}$ & $69,9 \mathrm{aA}$ & $54,1 \mathrm{bA}$ \\
Pretinha & $33,1 \mathrm{bB}$ & $61,2 \mathrm{aA}$ & $64,1 \mathrm{aA}$ \\
Pirarucu & $27,8 \mathrm{bB}$ & $26,2 \mathrm{bB}$ & $64,1 \mathrm{aA}$ \\
Paxiubão & $30,0 \mathrm{aB}$ & $26,2 \mathrm{aB}$ & $26,2 \mathrm{aB}$ \\
\hline
\end{tabular}

${ }^{(1)}$ Médias seguidas de mesma letra, minúscula nas linhas e maiúscula nas colunas, não diferem entre si $(\mathrm{P}>0,05)$, pelo teste de Tukey.

Tabela 3. Porcentagem de matéria seca de raízes e porcentagem de raízes podres de cultivares de mandioca submetidas a três freqüências de poda em duas alturas de poda. Rio Branco, Acre, 1999(1).

\begin{tabular}{|c|c|c|c|}
\hline \multirow[t]{2}{*}{ Cultivar } & \multicolumn{3}{|c|}{ Podas após plantio } \\
\hline & 6,12 e 18 meses & 12 e 18 meses & 18 meses \\
\hline & \multicolumn{3}{|c|}{ Porcentagem de matéria seca com corte a $0,50 \mathrm{~m}$ de altura } \\
\hline Metro III & $35,4 \mathrm{aA}$ & $32,0 \mathrm{bA}$ & $30,9 \mathrm{bB}$ \\
\hline Paxiúba II & $28,7 \mathrm{bB}$ & $30,4 \mathrm{bA}$ & $34,3 \mathrm{aA}$ \\
\hline Pretinha & $29,6 \mathrm{bB}$ & $30,2 \mathrm{bA}$ & $35,4 \mathrm{aA}$ \\
\hline Pirarucu & $23,5 \mathrm{cC}$ & $30,4 \mathrm{bA}$ & $35,3 \mathrm{aA}$ \\
\hline \multirow[t]{2}{*}{ Paxiubão } & $23,9 \mathrm{cC}$ & $28,1 \mathrm{bB}$ & $35,2 \mathrm{aA}$ \\
\hline & \multicolumn{3}{|c|}{ Porcentagem de matéria seca com corte a $1,00 \mathrm{~m}$ de altura } \\
\hline Metro III & $34,4 \mathrm{aA}$ & $32,9 \mathrm{aA}$ & $30,6 \mathrm{bD}$ \\
\hline Paxiúba II & $29,5 \mathrm{bC}$ & $30,9 \mathrm{bAB}$ & $33,5 \mathrm{aC}$ \\
\hline Pretinha & $32,0 \mathrm{bB}$ & $30,5 \mathrm{bB}$ & $35,9 \mathrm{aAB}$ \\
\hline Pirarucu & $26,4 \mathrm{bD}$ & $32,6 \mathrm{aA}$ & $34,1 \mathrm{aBC}$ \\
\hline \multirow[t]{2}{*}{ Paxiubão } & $33,0 \mathrm{bAB}$ & $31,8 \mathrm{bAB}$ & $37,1 \mathrm{aA}$ \\
\hline & \multicolumn{3}{|c|}{ Porcentagem de raízes podres com corte a $0,50 \mathrm{~m}$ de altura } \\
\hline Metro III & $3,9 \mathrm{aA}$ & $4,3 \mathrm{aB}$ & $0,1 \mathrm{aA}$ \\
\hline Paxiúba II & $2,8 \mathrm{aA}$ & $3,5 \mathrm{aB}$ & $0,6 \mathrm{aA}$ \\
\hline Pretinha & $2,6 \mathrm{abA}$ & $6,2 \mathrm{aB}$ & $0,6 \mathrm{bA}$ \\
\hline Pirarucu & $3,2 \mathrm{aA}$ & $0,9 \mathrm{aB}$ & $2,2 \mathrm{aA}$ \\
\hline \multirow[t]{2}{*}{ Paxiubão } & $8,0 \mathrm{bA}$ & $20,7 \mathrm{aA}$ & $1,7 \mathrm{cA}$ \\
\hline & \multicolumn{3}{|c|}{ Porcentagem de raízes podres com corte a $1,00 \mathrm{~m}$ de altura } \\
\hline Metro III & $2,2 \mathrm{aA}$ & $1,3 \mathrm{aB}$ & $6,1 \mathrm{aA}$ \\
\hline Paxiúba II & $5,2 \mathrm{aA}$ & $2,6 \mathrm{abAB}$ & $0,1 \mathrm{bB}$ \\
\hline Pretinha & $1,0 \mathrm{aA}$ & $2,1 \mathrm{aAB}$ & $0,1 \mathrm{aB}$ \\
\hline Pirarucu & $0,7 \mathrm{aA}$ & $1,1 \mathrm{aB}$ & $1,0 \mathrm{aAB}$ \\
\hline Paxiubão & 3,0abA & $7,6 \mathrm{aA}$ & $1,7 \mathrm{bB}$ \\
\hline
\end{tabular}

${ }^{(1)}$ Médias seguidas de mesma letra, minúscula nas linhas e maiúsculas nas colunas, não diferem entre si $(\mathrm{P}>0,05)$, pelo teste de Tukey. 
melhor qualidade (maior porcentagem de folhas) do que a obtida na poda única, aos 18 meses (Figuras 1, 2 e 3 ). As cultivares, quando podadas aos seis meses, tiveram recuperação da parte aérea seriamente comprometida; o rendimento de matéria seca proveniente da segunda poda aos doze meses foi muito reduzido, e por isso não foi apresentado na Figura 1; já a produção de matéria seca na terceira poda foi satisfatória.

A porcentagem de folhas (média das cinco cultivares nas duas alturas de poda) decresceu de $29,11 \%$, no sexto mês, para $11,65 \%$ aos 18 meses (Figura 1). Resultados semelhantes foram obtidos por Montaldo (1977) e Albuquerque \& Cardoso (1980), que concluíram que o aumento da idade das plantas afeta significativamente e negativamente a produção de folhagem. Esse declínio é mais drástico em relação à brotação proveniente das podas, conforme pode ser verificado no rendimento de matéria seca (limbo mais pecíolo) resultante da segunda poda efetuada aos 18 meses, que foi de $177,1 \%$ inferior ao da poda aos 12 meses (Figuras 2 e 3 ).

O rendimento de raízes foi reduzido significativamente tanto pela altura de poda como pela freqüên-

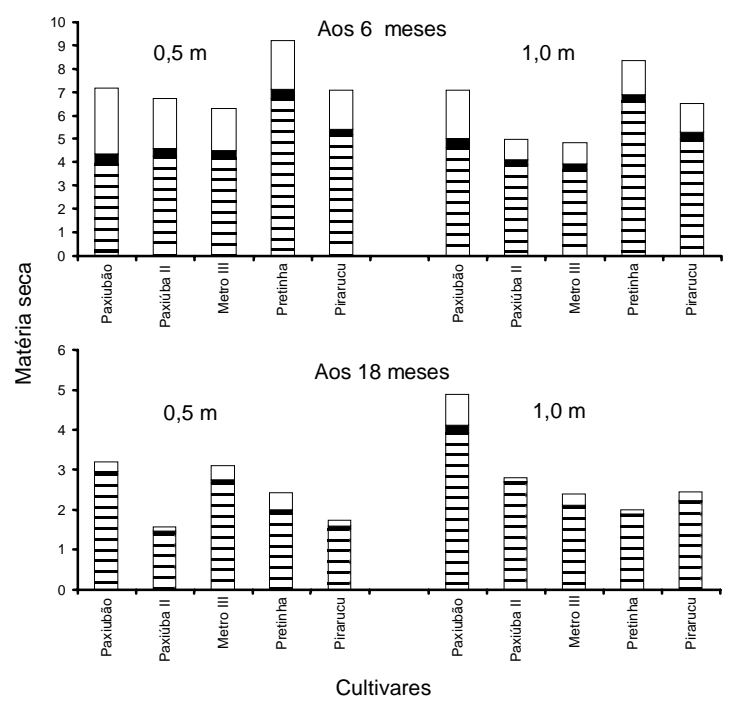

Figura 1. Matéria seca (t/ha) da parte aérea ( $\square$ Caule, - Pecíolo e $\square$ Limbo) de cinco cultivares de mandioca, submetidas à primeira poda aos seis meses, e à terceira poda aos 18 meses (na freqüência de três podas) a duas alturas de corte. cia de poda. As freqüências de duas e três podas provocaram redução significativa em relação à poda única, no rendimento de raízes das cultivares Metro III, Paxiúba II e Pirarucu (Tabela 2). Quando as cultivares foram submetidas a três podas $(6,12 \mathrm{e}$ 18 meses), os rendimentos de raízes decresceram, em média $90,6 \%$, e, em $70,7 \%$ quando foram podadas duas vezes (12 e 18 meses). A cultivar Paxiubão foi a única que não teve seus rendimentos de raízes afetados pelas podas; no entanto, foi a que apresentou o menor rendimento (Tabela 2).

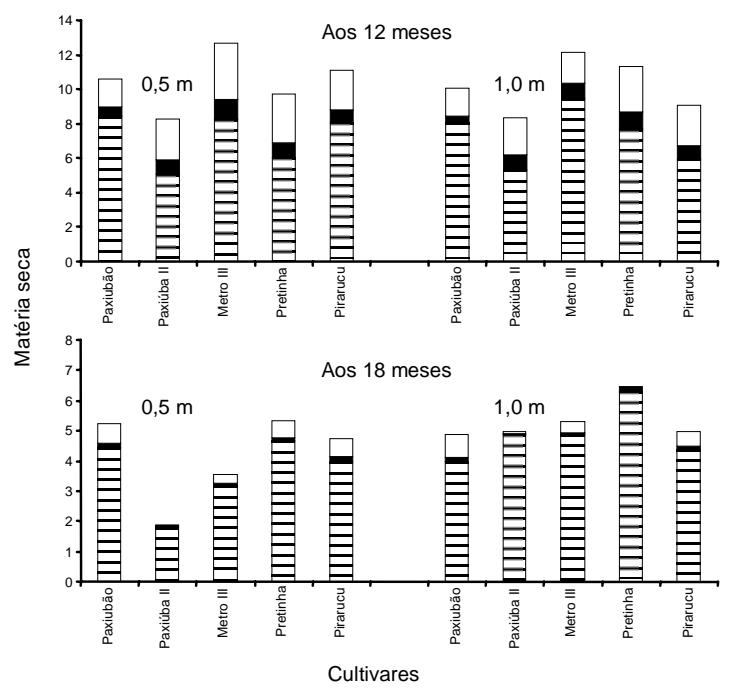

Figura 2. Matéria seca ( $\mathrm{t} / \mathrm{ha}$ ) da parte aérea (匹Caule, - Pecíolo e $\square$ Limbo) de cinco cultivares de mandioca, submetidas à primeira poda aos doze meses, e à segunda poda aos 18 meses (na freqüência de duas podas) a duas alturas de corte.

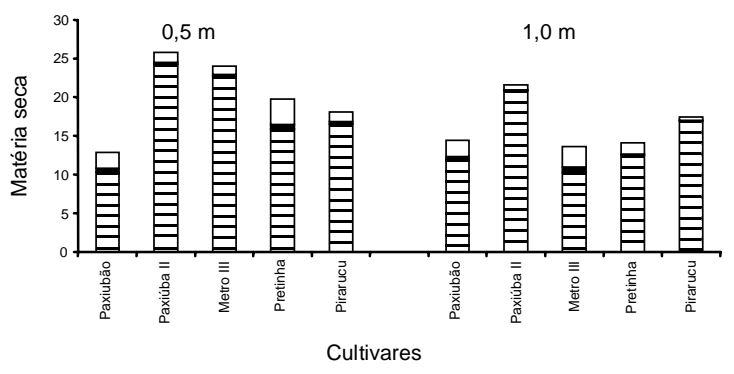

Figura 3. Matéria seca (t/ha) da parte aérea ( $\square$ Caule, - Pecíolo e $\square$ Limbo) de cinco cultivares de mandioca, submetidas à poda única aos 18 meses, a duas alturas de corte. 
Com exceção da cultivar Metro III, as demais apresentaram redução significativa na porcentagem de matéria seca de raízes, provocada pelas freqüências das podas (duas ou três), quando foram efetuadas a $0,50 \mathrm{~m}$ ou $1,00 \mathrm{~m}$ de altura. Admite-se que esse maior teor de umidade nas raízes seja resultante dos processos fisiológicos envolvidos na formação de novos ramos e folhas. Esses resultados são discordantes dos obtidos por Lorenzi et al. (1978), os quais, avaliando o efeito da poda sobre a cultivar Mantiqueira, verificaram que os teores de matéria seca não apresentaram reduções significativas. Em relação à matéria seca de raízes, a cultivar Metro III foi superior às demais quando submetidas a três podas a $0,50 \mathrm{~m}$ de altura, e não se diferenciou da Paxiubão quando as podas foram efetuadas a 1,00 m (Tabela 3).

As freqüências de poda a $0,50 \mathrm{~m}$ de altura não provocaram aumento significativo na porcentagem de raízes podres das cultivares Metro III, Pirarucu e Paxiúba II. Já a 1,00 m a cultivar Metro III foi a única que não apresentou elevação significativa no índice de podridão radicular (Tabela 3). A elevação do índice de podridão radicular pode estar relacionada com a queda de resistência das plantas, causada pela formação de novas estruturas vegetativas.

As cultivares Metro III, Pretinha e Pirarucu apresentaram redução significativa no teor de ácido cianídrico quando foram submetidas a três podas. Resultados semelhantes foram obtidos por Lorenzi et al. (1978), os quais constataram reduções evidentes no teor de ácido cianídrico, embora não tenham sido significativas (Tabela 3). Esses autores sugeriram que esse decréscimo de ácido cianídrico poderia estar envolvido no metabolismo do nitrogênio na formação de novas brotações.

\section{Conclusões}

1. A cultivar Paxiubão é adequada para o aproveitamento simultâneo da parte aérea e raízes.

2. O rendimento de raízes é afetado tanto pela altura de poda como pela freqüência de poda.

3. A redução da altura de poda e o aumento da freqüência de poda reduzem o teor de matéria seca das raízes, e elevam o índice de podridão das raízes.

4. A maior freqüência de poda reduz o teor de ácido cianídrico nas raízes.

\section{Agradecimentos}

Aos pesquisadores Francisco José da Silva Lédo, pela execução das análises estatísticas; a Celso Luís Bergo, pela elaboração das figuras e pelas sugestões apresentadas.

\section{Referências}

AHMAD, M. I. Potential fodder and tuber yield of two varieties of tapioca. Malaysian Agricultural Journal, Kuala Lumpur, v. 49, n. 2, p. 166-174, 1973.

AlbuQuerque, M. de; CARDoso, E. M. R. A mandioca no trópico úmido. Brasília : Editerra, 1980. $251 \mathrm{p}$.

BATISTA, M. A. M.; ALBUQUERQUE, M.; CAMARÃO, A. P.; BRAGA, E.; LOURENÇO JÚNIOR, J. de B. Digestibilidade "in vitro" e teores de proteína do farelo e da rama de cultivares de mandioca. Belém : Embrapa-CPATU, 1983a. 3 p. (Embrapa-CPATU. Comunicado Técnico, 43).

BATISTA, M. A. M.; ALBUQUERQUE, M.; CAMARÃO, A. P.; BRAGA, E.; LOURENÇO JÚNIOR, J. de B. Valor nutritivo da rama de mandioca. Belém : Embrapa-CPATU, 1983b. 3 p. (Embrapa-CPATU. Comunicado Técnico, 42).

CAMARÃO, A. P.; BATISTA, H. A. M.; LOURENÇO JÚNIOR, J. de B.; CARDOSO, E. M. R. Utilização da mandioca na alimentação de ruminantes na Amazônia. Belém : Embrapa-CPATU, 1993. 40 p. (Embrapa-CPATU. Documentos, 73).

CARVALHO, J. L. H.; PERIM, S.; COSTA, I. R. S. Parte aérea da mandioca na alimentação animal. I. Valor nutritivo e qualidade da silagem. Planaltina : EmbrapaCPAC, 1983. 6 p. (Embrapa-CPAC. Comunicado Técnico, 29).

CARVALHO, V. D.; PAULA, M. B. de; JUSTE JÚNIOR, E. S. G. Efeito da época de colheita no rendimento e composição química de fenos da parte aérea de dez cultivares de mandioca. Revista Brasileira de Mandioca, Cruz das Almas, v. 4, n. 1, p. 43-59, 1985.

CORREA, H.; OLIVEIRA, J. C. E.; STARLING, S.; RIBEIRO, F. Efeito da poda de ramas de mandioca na produção de ramas e raízes. Revista Ceres, Viçosa, v. 20, n. 1, p. 148-157, 1973. 
FUKUDA, W. M. G.; CALDAS, R. C. Influência da época de colheita sobre o comportamento de cultivares e clones de mandioca. Revista Brasileira de Mandioca, Cruz das Almas, v. 4, n. 2, p. 37-44, 1985.

GERODETTI, M. B. Efectos de la poda e laboreo del suelo sobre el crecimiento y rendimiento de yuca (Manihot esculenta Crantz) asociada con maíz (Zea mays L.) y vainita (Phaseolus vulgaris $L$.). Turrialba : Centro Agronómico Tropical de Investigación y Enseñanza, 1979. 93 p. Tesis de Maestría.

GROSSMAN, J.; FREITAS, A. C. Determinação do teor de matéria seca pelo peso específico em mandioca. Revista Agronômica, Porto Alegre, v. 14, n. 160/162, p. 75-80, 1950.

KATO, M. de S. A.; OLIVEIRA, R. P. de; KATO, O. R. Competição de cultivares de mandioca em diferentes ambientes da Transamazônica. Revista Brasileira de Mandioca, Cruz das Almas, v. 3, n. 2, p. 39-45, 1985.

LORENZI, J. O.; GUTIERREZ, L. E.; NORMANHA, E. S.; CIONE, S. Variação de carboidratos e ácido cianídrico em raízes de mandioca, após a poda da parte aérea. Bragantia, Campinas, v. 37, p. 139-144, 1978. Tomo único.

MEYRELES, L.; MacLEOD, N. A.; PRESTON, T. R. Forraje de yuca como fuente proteica: efecto de la densidad de población y edad de corte. Producción Animal Tropical, Santo Domingo, v. 2, n. 1, p. 18-26, 1977.

MONTALDO, A. Whole plant utilization of cassava for animal feed. In: NESTEL, B.; GRAHAN, M. (Ed.). Cassava as animal feed. Ottawa : International Development Research Center, 1977. p. 95-107.
MONTALDO, A.; MONTILLA, J. J. Production of cassava foliage. In: SYMPOSIUM OF THE INTERNATIONAL SOCIETY FOR TROPICAL ROOT CROPS, 4., 1976, Cali. Proceedings... Ottawa : International Development Research Center, 1977. p. 142-143.

OLIVEIRA, F. N. S. de; LIMA, J. A. de S. Introdução e avaliação de cultivares de mandioca (Manihot esculenta Crantz) em Rondônia. Porto Velho : Embrapa-UEPAE Porto Velho, 1986. 6 p. (Embrapa-UEPAE Porto Velho. Pesquisa em Andamento, 99).

OLIVEIRA, V. H.; ALVARENGA, M. I. N. Principais solos do Acre. Rio Branco : Embrapa-UEPAE Rio Branco, 1985. 40 p. (Embrapa-UEPAE Rio Branco. Documentos, 5).

PEZO, D.; BENAVIDES, J.; RUIZ, A. Producción de follaje y raíces de yuca (Manihot esculenta Crantz) bajo diferentes densidades de plantación y frecuencia de poda. Producción Animal Tropical, Santo Domingo, v. 9, n. 2, p. 251-262, 1984.

TEELUCK, J. P.; NICLIN, R.; HULMAN, B.; PRESTON, T. R. Apuntes sobre el uso de la yuca (Manihot esculenta) como fuente combinada de proteína y forraje para el crecimiento de becerros alimentados con dietas de melaza/ urea. Producción Animal Tropical, Santo Domingo, v. 6, n. 1, p. 90-93, 1981

WILLIAMS, H. J.; EDWARDS, T. G. Estimation cyanide with alkaline pricrate. Journal of the Science of Food Agriculture, Chichester, v. 31, p. 15-22, 1980. 